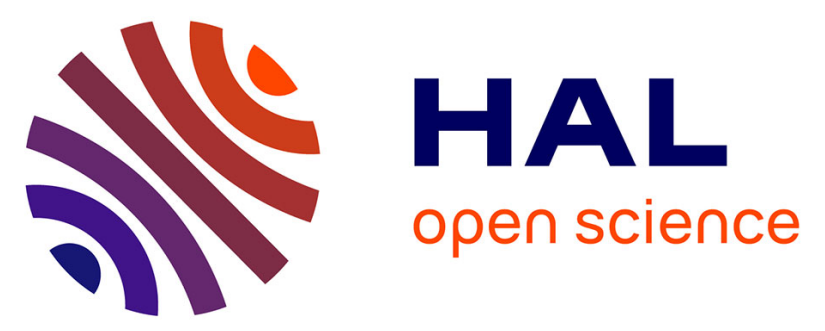

\title{
Decentralized Control of Voltage Source Converters in Microgrids based on the Application of Instantaneous Power Theory
}

Andres Ovalle, Gustavo Ramos, Seddik Bacha, Ahmad Hably, Axel Rumeau

\section{- To cite this version:}

Andres Ovalle, Gustavo Ramos, Seddik Bacha, Ahmad Hably, Axel Rumeau. Decentralized Control of Voltage Source Converters in Microgrids based on the Application of Instantaneous Power Theory. IEEE Transactions on Industrial Electronics, 2014, 62 (2), pp.1152-1162. 10.1109/TIE.2014.2336638 . hal-01064281

\section{HAL Id: hal-01064281 \\ https://hal.science/hal-01064281}

Submitted on 17 Sep 2014

HAL is a multi-disciplinary open access archive for the deposit and dissemination of scientific research documents, whether they are published or not. The documents may come from teaching and research institutions in France or abroad, or from public or private research centers.
L'archive ouverte pluridisciplinaire HAL, est destinée au dépôt et à la diffusion de documents scientifiques de niveau recherche, publiés ou non, émanant des établissements d'enseignement et de recherche français ou étrangers, des laboratoires publics ou privés. 


\title{
Decentralized control of Voltage Source Converters in Microgrids based on the Application of Instantaneous Power Theory
}

\author{
Andres Ovalle, Student Member, IEEE, Gustavo Ramos, Member, IEEE, Seddik Bacha, Member, IEEE, \\ Ahmad Hably, Member, IEEE, and Axel Rumeau
}

\begin{abstract}
In this paper, a new strategy to control microgrids highly penetrated by Voltage Source Converters (VSC) is proposed. The strategy is based on instantaneous measurements and calculations of voltages and currents and the application of Instantaneous Power Theory. This approach employs each VSC along with an LC filter as a current source. The grid parameters are not known to the controller, only the filter inductance and capacitance. The approach characterizes a theoretical methodology to define a grid status parameter that provides multiple alternatives to operate the VSC autonomously. Besides, one of those alternatives is sharing load among VSCs by regulating voltage of the local connection bus. This grid status parameter is an external voltage contribution vector defined by the operation of the other VSCs in the microgrid. Because of the definition of this parameter, frequency manipulation is not employed as a communication link between VSCs, avoiding perturbation to the grid stability. The approach provides an approximation of the equivalent impedance of the system seen from the filter output. The load sharing scheme under the proposed strategy is fully described. An experimental validation is performed in order to test the proposed approach for load sharing between three VSCs and the inclusion of nonlinear load.
\end{abstract}

Index Terms-Microgrid, Distributed Generation (DG), Instantaneous Power Theory, Voltage Source Converter (VSC), Gridconnected inverter, Current Control, Load Sharing.

\section{INTRODUCTION}

A Microgrid can be defined as a cluster of elements such as loads, distributed generators (DG) (kW-scale technologies such as combined heat and power devices, photovoltaic modules, small wind turbines, etc.), distributed storage units and controllable loads, connected through a medium or low voltage interconnecting power grid. Also, the microgrid can be understood as a subset or a constructive unit of the distribution system. When the number of elements in each microgrid

Manuscript received November 3, 2013; revised February 28 and March 20, 2014; and accepted 6 June, 2014.

Copyright (c) 2014 IEEE. Personal use of this material is permitted. However, permission to use this material for any other purposes must be obtained from the IEEE by sending a request to pubs-permission@ieee.org

This work was supported by the Faculty of Engineering, Universidad de los Andes, Colombia; the Grenoble Electrical Engineering Laboratory, France; and the ARC Energies Région Rhône-Alpes, France.

A. Ovalle, S. Bacha and A. Rumeau are with the Grenoble Electrical Engineering Laboratory, Grenoble 38402, France.

(andres.ovalle-villamil@g2elab.grenoble-inp.fr)

G. Ramos is with the Electrical and Electronics Department, School of Engineering, Universidad de los Andes, Bogotá 111711, Colombia.

A. Hably is with the Grenoble Image Parole Signal Automatique Laboratory, Grenoble 38402, France. is increased, the problem of controlling them can be very challenging in a centralized way. Thus, each microgrid has the responsibility of controlling their own units locally. In this way, from the point of view of the whole distribution system, the microgrid can be seen as a controlled entity, either generator or load [1], [2]. Security, reliability, environment impact, power quality and energy efficiency challenges for future electricity grids could meet their solution in the microgrid concept [3].

In grid-connected mode, the grid provides a robust frequency reference (because of the presence of large rotating masses) and it supplies the mismatch between DG generation and demand in the microgrid. An excess of generation can be stored or supplied to the grid and DGs can provide voltage support services to the grid [2]. In autonomous or standalone mode, load must be shared among generators, while frequency and voltage (active and reactive powers) must be controlled locally [4], [5]. While in grid-connected mode, DGs can behave like constant power sources, in autonomous mode, they must share load while keeping frequency and voltage within established security limits. The frequency response of large power systems is based on rotating masses, which are essential for the stability of the system [2]. However, in standalone mode there is a lack of rotating masses and the microgrid is highly dominated by DGs interfaced with power electronics converters. Another interesting fact is that a generator cannot be assumed to be connected to an infinite bus, and the system cannot be studied with conventional power flow techniques because none of the generators can be considered as a slack node [5]. The system dynamics are imposed by VSCs, power regulation controllers and the network variable parameters [6]. Although there are some important difficulties in the operation of grid-connected mode, autonomous mode has challenging problems to be analyzed as it can be stated.

Power electronics converters are key elements in the microgrid concept. They are employed to transform energy of the energy sources (DC or AC) to grid-compatible energy (AC at $50-60 \mathrm{~Hz}$ ), or grid-energy to energy compatible with the distributed storage units. Voltage Source converters (VSC) are power electronics converters employed to interface energy sources and storage units with the grid [3], [4], [7], [8].

The VSC topology definition employed in this work is shown on Fig. 1. Together the DC-AC converter and the lowpass passive filter on the right, will be considered as the DG unit. $L C$ filters are usually employed on industrial applications 


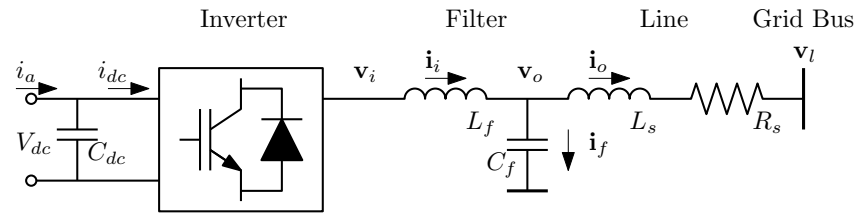

Fig. 1. VSC topology

to mitigate high frequency content on output current and voltage waveforms [9]. An interconnection line between the microgrid and the DG is modeled by parameters $R_{s}$ and $L_{s}$. Knowing that the microgrid is a low or medium voltage system, the resistive parameter of the line cannot be neglected.

When the interface impedance between a generator and a grid bus has a negligible resistive component, and the angular difference $\theta$ between the generator voltage and the bus voltage is very small, some behaviors can be assumed for active and reactive powers drawn by the bus. In this case, active power $P$ strongly depends on the angle $\theta$, while reactive power $Q$ depends on the voltage amplitude difference through the impedance [10], [11]. These relationships are exploited in large scale systems, where synchronous generators drop their frequencies when output power is increased. On the other hand, when the inductive part of the impedance is negligible, the roles are reversed. Reactive power $Q$ depends on the angle $\theta$, while active power $P$ depends on the voltage amplitude difference through the impedance [10], [11]. A VSC controlled with a conventional power sharing droop method employs artificial droops to emulate these behaviors [4], [12]. The basic idea is to mimic the governor of a synchronous generator [6]. One important advantage of this type of methods is that they offer the option of load sharing without communication links between DGs [13], [14]. This is desirable because the microgrid can span over a wide area [14]-[19].

The conventional frequency/voltage droop method is a wellstudied strategy, however it has important drawbacks. Although it is useful to share a common active load between DGs, the reactive power control scheme is strongly dependent on the grid parameters [4], [13], [20]. The power sharing accuracy is strongly affected by impedance unbalances and there exist a tradeoff between power sharing accuracy and output voltage regulation [12]. The imminent frequency and magnitude deviations can strongly affect the system stability [12]. High droop gains have a negative impact on stability of the system [14]. It is not suitable when nonlinear load is shared [13], [20]. Several works have been reported to overcome these problems and provide improved solutions to the control of stand-alone mode microgrids [4], [12], [21]-[25].

The aim of this paper is to provide the theoretical base and an experimental evaluation of a new strategy to control VSCs based on instantaneous measurements and calculations of voltages and currents and the application of Instantaneous Power Theory. The approach defines a theoretical methodology to define a grid status parameter that provides multiple alternatives to operate the VSC autonomously. One of the alternatives of the proposed technique achieves load sharing among VSCs. Contrarily to droop control based techniques, these alternative works without employing frequency fluctuation as a communication link between VSCs.

The paper is organized as follows. In section II a brief review of the Instantaneous power theory is presented, along with some important related facts. Section III describes the theoretical approach employed to formulate the new strategy. Also in this section, some important aspects of the strategy are presented along with a description of the multiple operative alternatives provided for the VSC. Section IV presents the extension of the proposed approach in order to manage nonlinear loads. Section V describes the proposed load sharing scheme. Section VI shows details of the controller of the VSCs, with the proposed strategy immersed. In section VII, the experimental validation is described along with the description of obtained experimental results. Finally, section VIII concludes the paper.

\section{Instantaneous Power THEORY}

The instantaneous power theory, or $p-q$ Theory, defines a set of instantaneous powers in the time domain. Since this theory does not impose any restriction to waveforms, it is applicable to non-sinusoidal currents and voltages and not only on steady state but also during transient states [26].

The Clarke transformation maps a three-phase system of instantaneous voltages or currents on the $a b c$ frame, into instantaneous voltages or currents on the $\alpha \beta 0$ frame. The transformation for generic quantities is given by,

$$
\left[\begin{array}{l}
\alpha \\
\beta \\
0
\end{array}\right]=\sqrt{\frac{2}{3}}\left[\begin{array}{ccc}
1 & \frac{-1}{2} & \frac{-1}{2} \\
0 & \frac{\sqrt{3}}{2} & \frac{-\sqrt{3}}{2} \\
\frac{1}{\sqrt{2}} & \frac{1}{\sqrt{2}} & \frac{1}{\sqrt{2}}
\end{array}\right]\left[\begin{array}{l}
a \\
b \\
c
\end{array}\right]
$$

On a three-phase three-wire system, the zero-sequence component of current do not exist. On a three-phase fourwire system the zero-sequence component of voltage do not exist if three-phase voltages are balanced. For example, let us assume a three-phase ideal voltage source feeding a three-phase balanced load. Applying a system of three-phase voltages containing only positive sequence on the fundamental frequency (sinusoidal and balanced) to the Clarke transformation, provides the following quantities on the $\alpha \beta$ frame,

$$
\left\{\begin{array}{l}
v_{\alpha}(t)=\sqrt{3} V \cos (\omega t) \\
v_{\beta}(t)=\sqrt{3} V \sin (\omega t)
\end{array}\right.
$$

The constant value $V$ is the RMS value of voltage waveforms on the three-phase system. Thus, the Clarke transformation represents a three-phase system of instantaneous quantities, in the fundamental positive sequence, as a rotating vector on the $\alpha \beta$ frame.

Instantaneous powers (instantaneous real power $p$ and instantaneous imaginary power $q$ ) in the $p-q$ Theory are defined by $p=v_{\alpha} i_{\alpha}+v_{\beta} i_{\beta}$ and $q=v_{\beta} i_{\alpha}-v_{\alpha} i_{\beta}$, or equivalently by the following two expressions [26].

$$
\begin{aligned}
& {\left[\begin{array}{l}
p \\
q
\end{array}\right]=\left[\begin{array}{cc}
v_{\alpha} & v_{\beta} \\
v_{\beta} & -v_{\alpha}
\end{array}\right]\left[\begin{array}{l}
i_{\alpha} \\
i_{\beta}
\end{array}\right]} \\
& {\left[\begin{array}{l}
p \\
q
\end{array}\right]=\left[\begin{array}{cc}
i_{\alpha} & i_{\beta} \\
-i_{\beta} & i_{\alpha}
\end{array}\right]\left[\begin{array}{l}
v_{\alpha} \\
v_{\beta}
\end{array}\right]}
\end{aligned}
$$




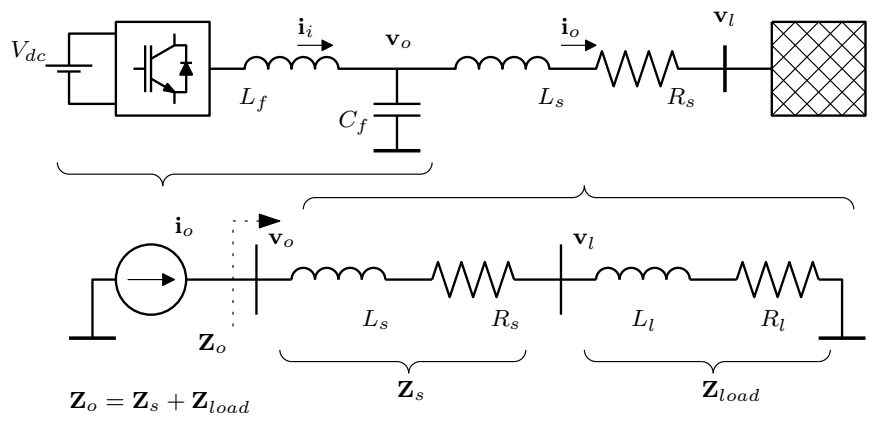

Fig. 2. VSC current source scheme proposed

Additionally, the instantaneous zero-sequence power is defined by $p_{0}=v_{0} i_{0}$. Applying these definitions to the case where the three-phase system of sinusoidal balanced voltages feed a linear load (which draws sinusoidal current waveforms), gives the following expressions for instantaneous real and imaginary powers.

$$
\left\{\begin{array}{l}
p=3 V I \cos (\phi) \\
q=-3 V I \sin (\phi)
\end{array}\right.
$$

These expressions are equal to the conventional definitions of three-phase active and reactive powers. As it can be noticed, real and imaginary instantaneous powers are constant (average powers) over time when voltages and currents exhibit only positive sequence on the fundamental frequency. It should be noticed that if voltages and powers are known variables, currents can be determined by applying the inverse matrix in (2). On the other hand, if currents and powers are known variables, voltages can be determined by applying the inverse matrix in (3). Expressions resulting from these procedures are given by,

$$
\begin{aligned}
& {\left[\begin{array}{l}
i_{\alpha} \\
i_{\beta}
\end{array}\right]=\frac{1}{v_{\alpha}^{2}+v_{\beta}^{2}}\left[\begin{array}{cc}
v_{\alpha} & v_{\beta} \\
v_{\beta} & -v_{\alpha}
\end{array}\right]\left[\begin{array}{l}
p \\
q
\end{array}\right]} \\
& {\left[\begin{array}{l}
v_{\alpha} \\
v_{\beta}
\end{array}\right]=\frac{1}{i_{\alpha}^{2}+i_{\beta}^{2}}\left[\begin{array}{cc}
i_{\alpha} & -i_{\beta} \\
i_{\beta} & i_{\alpha}
\end{array}\right]\left[\begin{array}{l}
p \\
q
\end{array}\right]}
\end{aligned}
$$

\section{New Approach - Strategy to Find $\phi_{e x}$}

Let us assume that VSCs with their corresponding LC filters behave like current sources. The current source is connected to a grid through a line with parameters $L_{s}$ and $R_{s}$ as shown on Fig. 2.

In a first case, the local current source is not operating $\left(\mathbf{i}_{o}=0\right)$, while the other sources are working. Therefore there is no voltage drop over the line and $\mathbf{v}_{o}=\mathbf{v}_{l}$. By the superposition theorem, the voltage $\mathbf{v}_{l}$ is the algebraic sum of voltages $\mathbf{v}_{l_{\rho}}$, each one contributed by the generator $\rho$ acting alone.

In a second case, the local source is working $\left(\mathbf{i}_{o} \neq 0\right)$, while the other sources are not operating (zero output current). Assuming steady state, if quantities are treated like phasors, $\mathbf{v}_{o}=\mathbf{Z}_{o} \mathbf{i}_{o}$, where $\mathbf{Z}_{o}$ is the equivalent impedance from the filter output as seen on Fig. 2. Thus, the angular displacement between $\mathbf{i}_{o}$ and $\mathbf{v}_{o}$, and the magnitude of $\mathbf{v}_{o}$, will remain constant under variations on the phase angle $\phi_{i_{o}}$ of $\mathbf{i}_{o}$.

$$
\mathbf{v}_{o}=\mathbf{v}_{l c}+\sum_{\rho=2}^{M} \mathbf{v}_{l_{\rho}}=\mathbf{v}_{l c}+\mathbf{v}_{e x}
$$

Assuming each source has a corresponding index $\rho$ and the local source is $\rho=1, \mathbf{v}_{o}$ is the sum of voltages contributed by each source operating alone, and is given by (7). $\mathbf{v}_{l c}$ is the contribution of the local current source and $\mathbf{v}_{e x}$ is the sum of the contributions from the other sources. As it was explained before, $\mathbf{v}_{e x}$ is fully independent from $\mathbf{i}_{o}$, while $\mathbf{v}_{l c}$ depends on $\mathbf{i}_{o}$ and the equivalent impedance $\mathbf{Z}_{o}$, and is completely independent from other generators.

$$
\begin{aligned}
& \left\{\begin{array}{l}
i_{o \alpha}=\sqrt{3} I_{o} \cos \left(\omega t+\phi_{i_{o}}\right) \\
i_{o \beta}=\sqrt{3} I_{o} \sin \left(\omega t+\phi_{i_{o}}\right)
\end{array}\right. \\
& \left\{\begin{array}{l}
v_{o \alpha}=\sqrt{3} V_{o} \cos \left(\omega t+\phi_{v}\right) \\
v_{o \beta}=\sqrt{3} V_{o} \sin \left(\omega t+\phi_{v}\right)
\end{array}\right.
\end{aligned}
$$

Let us assume $\mathbf{i}_{o}$ and $\mathbf{v}_{o}$ are vectors representing three-phase positive-sequence currents and voltages, on the $\alpha \beta$ frame. The instantaneous representation of their components are given by (8) and (9) respectively, where $I_{o}$ and $V_{o}$ are the corresponding RMS values of the $a b c$ quantities.

$$
\begin{aligned}
& \left\{\begin{array}{l}
v_{o \alpha}=v_{\alpha_{l c}}+v_{\alpha_{e x}} \\
v_{o \beta}=v_{\beta_{l c}}+v_{\beta_{e x}}
\end{array}\right. \\
& \left\{\begin{array}{l}
v_{\alpha_{l c}}=\sqrt{3} V_{l c} \cos \left(\omega t+\phi_{l c}\right) \\
v_{\beta_{l c}}=\sqrt{3} V_{l c} \sin \left(\omega t+\phi_{l c}\right)
\end{array}\right. \\
& \left\{\begin{array}{l}
v_{\alpha_{e x}}=\sqrt{3} V_{e x} \cos \left(\omega t+\phi_{e x}\right) \\
v_{\beta_{e x}}=\sqrt{3} V_{e x} \sin \left(\omega t+\phi_{e x}\right)
\end{array}\right.
\end{aligned}
$$

The $\alpha \beta$ components of $\mathbf{v}_{o}$ can be disaggregated into the local and external voltage contributions given by (10). These local and external contributions can be described in an instantaneous way. Because of the linearity of the system and the homogeneity in the frequency of all the current sources, $\alpha \beta$ components of the external contribution are sums of sinusoidal functions which are sinusoidal functions as well. The $\alpha \beta$ components of the local term are evidently sinusoidal because they depend only on $\mathbf{i}_{o}$. Local and external $\alpha \beta$ components are described by (11) and (12) respectively. It is important to notice that $V_{l c}=I_{o}\left|\mathbf{Z}_{o}\right|$, and $\phi_{l c}=\phi_{i_{o}}+\phi_{z_{o}}$, where $\phi_{z_{o}}$ is the phase angle of the equivalent impedance.

However, a practical superposition analysis is not viable because it requires turning off generators, interrupting the power supply to loads. Thus, measuring $v_{\alpha_{l c}}, v_{\alpha_{e x}}, v_{\beta_{l c}}$ and $v_{\beta_{e x}}$ is not possible, only quantities $v_{o \alpha}$ and $v_{o \beta}$ are available to be measured and the local and external quantities are immersed in these measurements.

\section{A. Instantaneous power theory application}

Instantaneous real and imaginary powers are defined by $p=$ $v_{\alpha} i_{\alpha}+v_{\beta} i_{\beta}$ and $q=v_{\beta} i_{\alpha}-v_{\alpha} i_{\beta}$ respectively [26]. Computing 
these expressions with (8) and (9) provides,

$$
\left\{\begin{array}{l}
p=3 V_{o} I_{o} \cos \left(\phi_{v_{o}}-\phi_{i_{o}}\right) \\
q=3 V_{o} I_{o} \sin \left(\phi_{v_{o}}-\phi_{i_{o}}\right)
\end{array}\right.
$$

Instantaneous powers are constant and independent of time because voltages and currents have only fundamental positivesequence components. Real and imaginary powers can be computed with (8) and (10) as well.

$$
\left\{\begin{array}{l}
p=3 V_{l c} I_{o} \cos \left(\phi_{l c}-\phi_{i_{o}}\right)+3 V_{e x} I_{o} \cos \left(\phi_{e x}-\phi_{i_{o}}\right) \\
q=3 V_{l c} I_{o} \sin \left(\phi_{l c}-\phi_{i_{o}}\right)+3 V_{e x} I_{o} \sin \left(\phi_{e x}-\phi_{i_{o}}\right)
\end{array}\right.
$$

Expressions on (13) and (14) are equivalent. Although $p$ and $q$ are the only possible quantities to be measured, it should be noticed that they can also be disaggregated in local and external contributions $p=p_{l c}+p_{e x}$ and $q=q_{l c}+q_{e x}$.

$$
\left\{\begin{array}{l}
p=3 V_{l c} I_{o} \cos \left(\phi_{z_{o}}\right)+3 V_{e x} I_{o} \cos \left(\phi_{e x}-\phi_{i_{o}}\right) \\
q=3 V_{l c} I_{o} \sin \left(\phi_{z_{o}}\right)+3 V_{e x} I_{o} \sin \left(\phi_{e x}-\phi_{i_{o}}\right)
\end{array}\right.
$$

Taking into account that $\phi_{l c}=\phi_{i_{o}}+\phi_{z_{o}}$, where $\phi_{z_{o}}$ is the phase angle of the equivalent impedance, expressions on (15) indicate that under variations of $\phi_{i_{o}}$, powers $p_{l c}$ and $q_{l c}$ remain constant while $p_{e x}$ and $q_{e x}$ change. Furthermore, the maximum real power transfer is achieved when $\phi_{i}=\phi_{e x}$, i.e., when the current is in phase with the sum of external voltage contributions.

$$
\begin{aligned}
\frac{\partial p}{\partial \phi_{i_{o}}} & =\frac{\partial p_{e x}}{\partial \phi_{i_{o}}}=3 V_{e x} I_{o} \sin \left(\phi_{e x}-\phi_{i_{o}}\right) \\
\frac{\partial q}{\partial \phi_{i_{o}}} & =\frac{\partial q_{e x}}{\partial \phi_{i_{o}}}=-3 V_{e x} I_{o} \cos \left(\phi_{e x}-\phi_{i_{o}}\right)
\end{aligned}
$$

As it was mentioned before, the local contributions to $p$ and $q$ remain constant under variations on $\phi_{i_{o}}$. Hence, the variations on $p$ and $q$ under variations of $\phi_{i_{o}}$ are equal to the variations on $p_{e x}$ and $q_{e x}$ under variations of $\phi_{i_{o}}$, respectively. These behaviors are represented in (16) and (17) which are the partial derivatives of $p$ and $q$ with respect to $\phi_{i_{o}}$.

$$
\begin{gathered}
V_{e x} \approx \frac{\sqrt{\Delta p^{2}+\Delta q^{2}}}{3 I_{o} \Delta \phi_{i_{o}}} \\
\phi_{e x} \approx \phi_{i_{o}}+\tan ^{-1}\left(\frac{\Delta p}{-\Delta q}\right)
\end{gathered}
$$

It should be noticed that $\partial p / \partial \phi_{i_{o}}=q_{e x}$ and $\partial q / \partial \phi_{i_{o}}=$ $-p_{e x}$. With small finite variations in $\phi_{i_{o}}$, the system can be perturbed and the consequent changes in $p$ and $q$ can be employed to approximate the partial derivatives with $\Delta p / \Delta \phi_{i_{o}}$ and $\Delta q / \Delta \phi_{i_{o}}$. These approximations provide an evidence of the quantities $p_{e x}$ and $q_{e x}$ which can be employed to compute an approximation to the external voltage contribution $\mathbf{v}_{e x}$. Therefore, the approximate RMS value of the external voltage contribution is given by (18), while an approximation of its angle is given by (19).

$$
\left\{\begin{array}{l}
p_{l c}=p-p_{e x} \\
q_{l c}=q-q_{e x}
\end{array}\right.
$$

With the approximation of external power contributions, local power contributions can be computed with (20). The obtained approximations for the local power contributions are an important output of the proposed strategy. These powers provide information of the equivalent impedance of the grid $\mathbf{Z}_{o}$, seen from the output of the generator (the generator is assumed as the ensemble inverter-filter) as it is shown on Fig. 2.

$$
\begin{gathered}
V_{l c}=\frac{\sqrt{p_{l c}^{2}+q_{l c}^{2}}}{3 I_{o}} \\
\left|Z_{o}\right|=\frac{V_{l c}}{I_{o}}=\frac{\sqrt{p_{l c}^{2}+q_{l c}^{2}}}{3 I_{o}^{2}} \\
\phi_{Z_{o}}=\tan ^{-1}\left(\frac{q_{l c}}{p_{l c}}\right)
\end{gathered}
$$

Once the approximations to the local power contributions are found, the approximate RMS value of the local voltage contribution is given by (21). Thus, the approximate magnitude of the equivalent impedance can be computed with (22), while the equivalent impedance angle can be computed with (23).

\section{B. Alternative calculations}

Real and imaginary instantaneous powers can also be computed with components on the rotative $d q$ reference frame as follows [26],

$$
\left[\begin{array}{l}
p \\
q
\end{array}\right]=\left[\begin{array}{cc}
i_{d} & i_{q} \\
-i_{q} & i_{d}
\end{array}\right]\left[\begin{array}{l}
v_{d} \\
v_{q}
\end{array}\right]
$$

Thus, if currents and powers are known variables and voltages are unknowns, then the inverse of the matrix of currents can be applied to the expression above and the unknown voltages can be obtained as follows [26],

$$
\left[\begin{array}{l}
v_{d} \\
v_{q}
\end{array}\right]=\frac{1}{i_{d}^{2}+i_{q}^{2}}\left[\begin{array}{cc}
i_{d} & -i_{q} \\
i_{q} & i_{d}
\end{array}\right]\left[\begin{array}{l}
p \\
q
\end{array}\right]
$$

With (24), and the discrete approximations to the external contributions of real and imaginary power $p_{e x}=-\Delta q / \Delta \phi_{i_{o}}$ and $q_{e x}=\Delta p / \Delta \phi_{i_{o}}$, the external voltage contribution can be computed.

$$
\begin{gathered}
{\left[\begin{array}{l}
v_{d_{e x}} \\
v_{q_{e x}}
\end{array}\right] \approx \frac{1}{i_{o d}^{2}+i_{o q}^{2}}\left[\begin{array}{cc}
i_{o d} & -i_{o q} \\
i_{o q} & i_{o d}
\end{array}\right]\left[\begin{array}{c}
-\Delta q \\
\Delta p
\end{array}\right] \frac{1}{\Delta \phi_{i_{o}}}} \\
\mathbf{v}_{l c}=\mathbf{v}_{o}-\mathbf{v}_{e x}
\end{gathered}
$$

The external voltage contribution components on the $d q$ frame are given by (25). As it was mentioned before, the output current should be in phase with this voltage in order to get maximum real power transference to the grid. With $\mathbf{v}_{e x}$ defined on the $d q$ frame and the measurement of $\mathbf{v}_{o}$, the local voltage contribution vector $\mathbf{v}_{l c}$ can be computed with (26).

\section{Controlling output current angle $\phi_{i_{o}}$ and output powers}

The vector diagram on Fig. 3(a) can be constructed as a result of the outcomes of the proposed strategy $\left(\mathbf{v}_{e x}, \phi_{e x}, \mathbf{Z}_{o}\right.$, $\left.\phi_{Z_{o}}, \mathbf{v}_{l c}\right)$

If the reference frame is always chosen to be aligned with the output current vector as in Fig. 3(a), the effect of rotating $\mathbf{i}_{o}$ by an amount $\phi_{i_{o}}$ is observed in this frame as a rotation of $\mathbf{v}_{e x}$ by an amount $-\phi_{i_{o}}$. On the other hand, the local voltage 

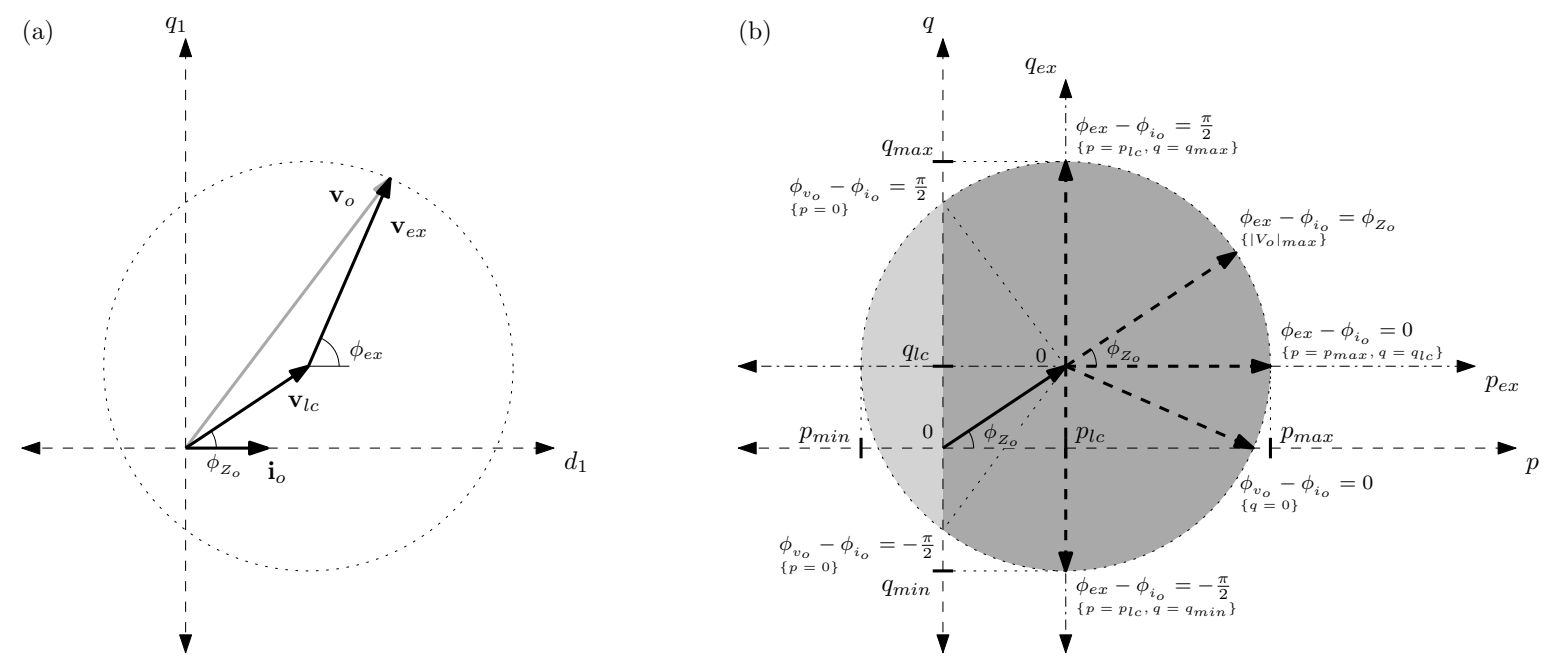

Fig. 3. VSC control strategy: (a) $d_{1} q_{1}$ reference frame with $d_{1}$ axis always aligned with output current, (b) $p-q-\phi_{i_{o}}$ control diagram

contribution vector $\mathbf{v}_{l c}$ maintains it angular difference $\phi_{Z_{o}}$ with respect to $\mathbf{i}_{o}$ because rotating the output current vector does not affect the equivalent impedance at all. Assuming a reference frame with the $d$ axis aligned always with the output current vector $\mathbf{i}_{o}$, the external voltage contribution vector $\mathbf{v}_{e x}$ can be rotated within this frame, in order to manipulate the instantaneous powers supplied by the VSC.

Fig. 3(b) shows some of the multiple available alternatives to control the instantaneous output powers. This Fig. shows the case of inductive equivalent impedance. These alternatives can be achieved once the external voltage contribution angle $\phi_{e x}$ and the equivalent impedance angle $\phi_{z_{o}}$ are found. With the control action of $\phi_{i_{o}}$, the output real and imaginary powers lie in the circumference shown in this figure.

The first alternative consists in obtaining maximum real output power. This alternative is achieved when $\phi_{e x}-\phi_{i_{o}}=0$. In this case, the external voltage contribution vector $\mathbf{v}_{e x}$ is aligned with the output current vector $\mathbf{i}_{o}$, maximizing the external real power contribution $p_{e x}$, while the external imaginary power contribution is $q_{e x}=0$.

The second alternative consists in obtaining maximum output voltage amplitude. This alternative is achieved when $\phi_{e x}-\phi_{i_{o}}=\phi_{z_{o}}$. In this case, the external voltage contribution vector $\mathbf{v}_{e x}$ is aligned with the local voltage contribution vector $\mathbf{v}_{l c}$, maximizing the magnitude of the output voltage vector $\mathbf{v}_{o}=\mathbf{v}_{l c}+\mathbf{v}_{e x}$ and the magnitude of the vector of powers $\sqrt{\left(p_{l c}+p_{e x}\right)^{2}+\left(q_{l c}+q_{e x}\right)^{2}}$.

The third alternative consists in obtaining maximum imaginary output power. This alternative is achieved when $\phi_{e x}-$ $\phi_{i_{o}}=\pi / 2$. In this case, the external voltage contribution vector $\mathbf{v}_{e x}$ is perpendicular to the output current vector $\mathbf{i}_{o}$ (output current lagging external voltage contribution), maximizing the external imaginary power contribution $q_{e x}$, while the external real power contribution is $p_{e x}=0$.

The fourth alternative consists in obtaining minimum imaginary output power. This alternative is achieved when $\phi_{e x}-$ $\phi_{i_{o}}=-\pi / 2$. In this case, the external voltage contribution vector $\mathbf{v}_{e x}$ is perpendicular to the output current vector $\mathbf{i}_{o}$ (output current leading external voltage contribution), minimizing the external imaginary power contribution $q_{e x}$, while the external real power contribution is $p_{e x}=0$. If $\left|\mathbf{v}_{e x}\right| \geq\left|\mathbf{v}_{l c}\right|$, it is possible to obtain a capacitive behavior (negative $q_{m i n}$ ).

The fifth alternative consists in obtaining zero imaginary output power. This alternative is achieved when $\phi_{v}-\phi_{i_{o}}=0$. In this case, the output voltage vector $\mathbf{v}_{o}$ is aligned with the output current vector $\mathbf{i}_{o}$, compensating the local imaginary power contribution with the external imaginary power contribution. This is possible only if $\left|\mathbf{v}_{e x}\right| \geq\left|\mathbf{v}_{l c}\right|$.

Additional alternatives can be explored. For example, there are two grayed areas on Fig. 3. The dark grayed area corresponds to the portion of the circumference to the right of the $q$ axis, where the preceding alternatives lie. Here the VSC behaves like a generator. The light grayed area corresponds the portion of the circumference to the left of the $q$ axis, where the generator absorbs real power, behaving like a controllable load or like a storage unit. This last portion of the circumference is defined by the angular differences $\phi_{v}-\phi_{i}=\pi / 2$ and $\phi_{v}-\phi_{i}=-\pi / 2$, where the output voltage vector $\mathbf{v}_{o}$ is perpendicular to the output current vector $\mathbf{i}_{o}$ and the real output power $p=p_{l c}+p_{e x}$ is zero. This alternative is also possible only if $\left|\mathbf{v}_{e x}\right| \geq\left|\mathbf{v}_{l c}\right|$.

In the case of maximum output voltage amplitude $\left|\mathbf{v}_{o}\right|_{\max }$, it is possible to manipulate the magnitude value of the output current vector $\mathbf{i}_{o}$ while maintaining the angular difference $\phi_{e x}-\phi_{i_{o}}=\phi_{z_{o}}$. This parameter can be manipulated in order to share load while regulating the output voltage magnitude and keep it within security levels. Besides, a stability limit can established when the magnitude of the output current cannot be increased enough to secure output voltage magnitude within these security levels.

\section{NONLINEAR LOAD MANAGEMENT}

Let us assume there is a nonlinear load on the microgrid, then a similar analysis to the one shown on Fig. 2 and section III can be applied. If the control action is only applied to fundamental positive sequence output current $\mathbf{i}_{o f}$, then the nonlinear load will be excited and will consume a portion of the fundamental current $\mathbf{i}_{r f}$. At the same time it will inject 


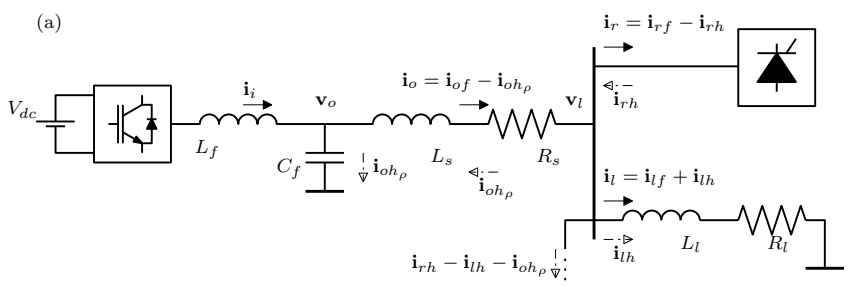

(b)

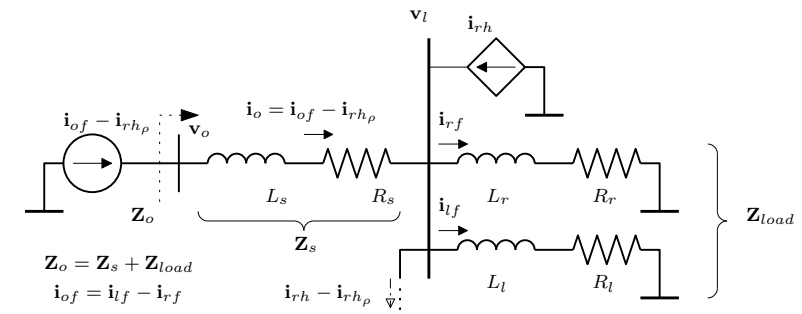

Fig. 4. VSC as harmonic compensator, Approach followed.

harmonic currents to the grid, represented on the quantity $\mathbf{i}_{r h}$. A portion $\mathbf{i}_{o h_{\rho}}$ of these currents will naturally flow through the grid to the capacitors of the filters (which represent small impedances at higher frequencies) corresponding to each VSC (with sub-index $\rho$ ), while the other portion $\mathbf{i}_{l h}$ will flow through the linear loads. This last portion will cause the appearance of harmonic components on the voltages of the grid. This scenario is represented on Fig. 4(a).

Assuming that the harmonic components of the grid voltages are eliminated by some additional control action over the VSCs output currents, then the currents consumed by the linear loads will have only fundamental component. This implies that the harmonic currents $\mathbf{i}_{r h}$ generated by the nonlinear loads are consumed by the VSCs. Then an equivalent scenario can be formulated in Fig. 4(b). Here, the nonlinear loads are equivalently represented by a controlled current source injecting harmonic currents and an effective portion of load consuming fundamental component of current (represented with parameters $L_{r}$ and $R_{r}$ ). At the same time, the equivalent linear load is represented with parameters $L_{l}$ and $R_{l}$. This two linear loads $\left(\mathbf{Z}_{\text {load }}\right)$ and the impedance of the connection line, represent the equivalent impedance that the proposed technique is able to find without any modification. The harmonic current source is a controlled source depending on the voltages feeding the nonlinear loads. However, given the fact that it does not provide any fundamental component of current, it can be neglected from the superposition analysis, which is performed over fundamental positive sequence sources of current.

Given the fact that the $X / R$ ratio is very small in this type of systems $(R>>X)$, then the harmonic components of the voltage $\mathbf{v}_{l h}$ on the linear portion of the load can be evidenced on the harmonic components $\mathbf{v}_{o h}$ of the voltage $\mathbf{v}_{o}$ on the capacitor on the filter of the VSC. On the other hand, given that inductive loads increase their impedance at higher frequencies, then it is assumed that the harmonics on the equivalent linear load are proportional to the resistive portion of $\mathbf{Z}_{o}$. Assuming a close to unity power factor on the equivalent linear load, then (a)
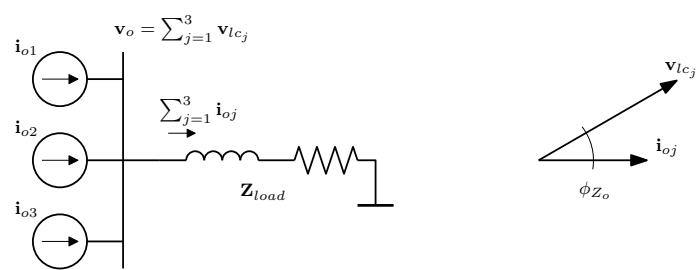

(b)

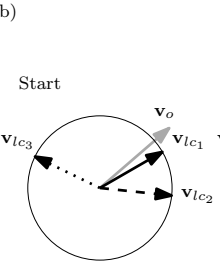

Local Contribution Voltages
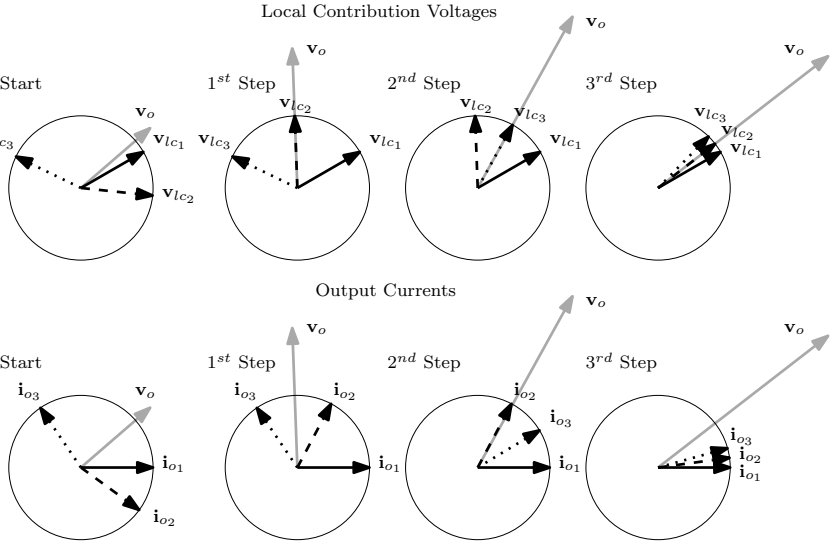

Fig. 5. Power sharing approach. Diagrams for explanation

the harmonic currents $\mathbf{i}_{l h}$ flowing through the linear loads are approximated by,

$$
\mathbf{i}_{l h} \approx \frac{\mathbf{v}_{o h}}{\left|\mathbf{Z}_{o}\right|}+\mathbf{i}_{o h_{\rho}}\left|\mathbf{Z}_{s}\right|
$$

The second term can be eliminated because the impedance of the line can be neglected. As a consequence, a benefit of finding $\mathbf{Z}_{o}$ is that every VSC has valuable information to be able to correct the harmonics on the voltage of the grid. To achieve that, besides the corresponding $\mathbf{i}_{o h_{\rho}}$ attracted by the capacitor, the VSCs have to consume a portion of the harmonic current $\mathbf{i}_{l h}$ proportional to the number of VSCs.

$$
\mathbf{i}_{d q_{o}} \approx \frac{\mathbf{v}_{o h}}{M\left|\mathbf{Z}_{o}\right|}-\mathbf{i}_{o h_{\rho}}
$$

Following the sign convention of Fig. 4, expression (27) is included as an additional term for the reference of the output current in order to share the consumption of the harmonic currents, and as a consequence, the compensation of voltage harmonics.

The unbalanced condition condition is not treated in this manuscript. However, as the VSC controls the fundamental positive sequence output current, the effect of unbalanced load will be observed in the voltage of the capacitor as well. The result will be zero and negative sequence components. The information to compute the equivalent impedance $\mathbf{Z}_{o}$ is available in the positive sequence component of the voltage while the other to components will provide information of the unbalance. As in the case of harmonic content, the controller has to act over negative and zero sequences with the information provided by the strategy, in order to share the compensation of the unbalanced voltages. 
(a)

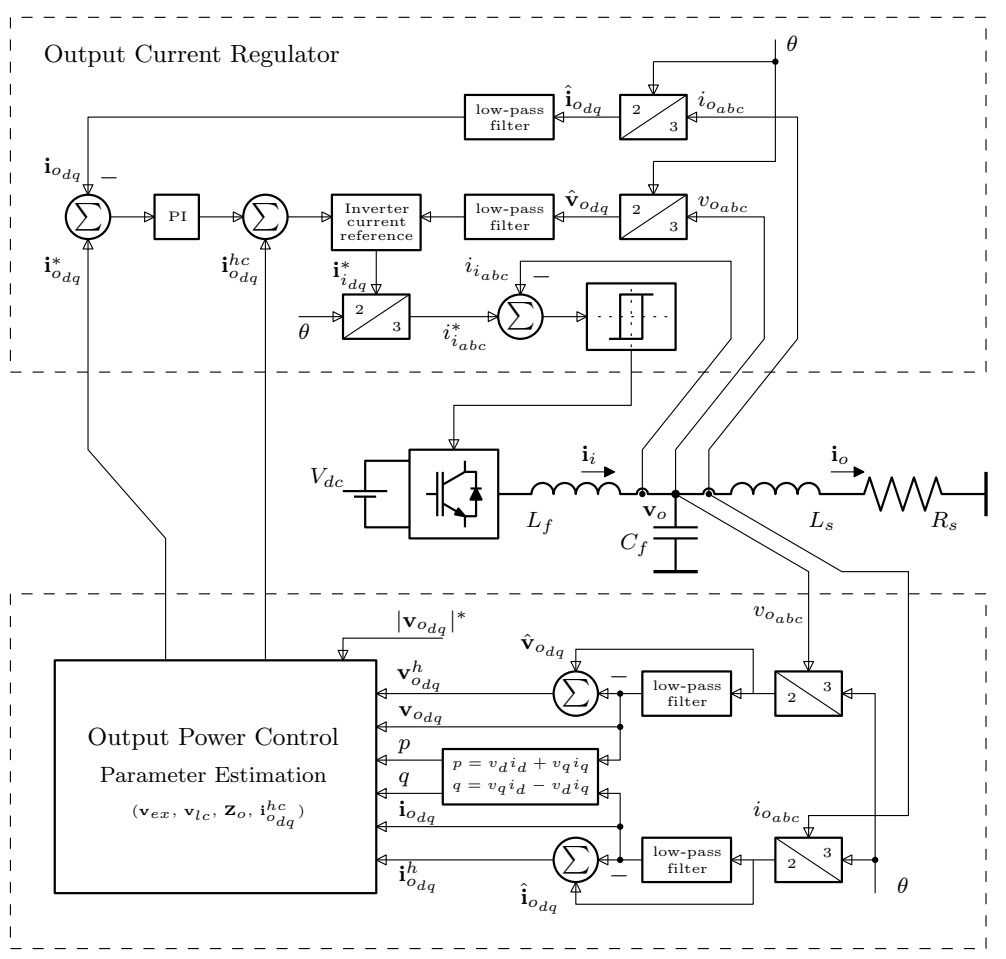

(b)

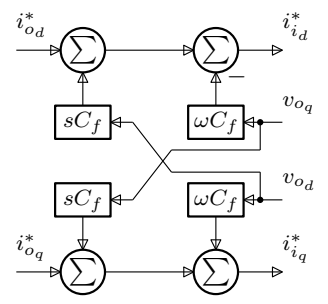

(c)

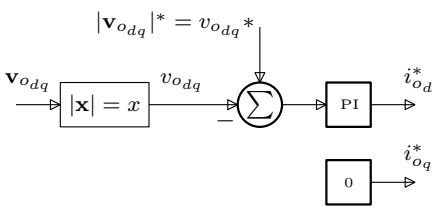

Fig. 6. Block diagram of the control approach. The "Output Power Control, Parameter Estimation" block performs the proposed strategy and provides the references for the output current fundamental positive sequence $\mathbf{i}_{o_{d} q}^{*}$, and the $d q$ components for compensation of harmonic currents $\mathbf{i}_{o_{d}}^{h c}$.

\section{Maximum output Voltage - LoAd Sharing}

The power sharing approach that can be followed from the proposed strategy (maximum output voltage alternative) can be described with Fig. 5. The microgrid can be simplified as a set of current sources providing its output current to a bus where an equivalent load is connected as it is shown on Fig. 5(a). Thus, each current vector and its corresponding local voltage contribution have a phase difference between them, which is equal to the phase angle of the impedance $\phi_{Z_{o}}$. For the purpose of the explanation, current and local voltage vectors are assumed unitary. Fig. 5(b) shows a random disposition of the local voltage vectors and their corresponding current vectors (out of phase by $\phi_{Z_{o}}$ ) at a start point. Let us assume that the first generator is a reference generator which does not perform any phase displacement. Thus, looking for maximizing its output voltage, the second generator displaces its current vector in order to align its local voltage vector with the sum of the other two local voltage vectors (the external voltage contribution) corresponding to generators 1 and 3 . This results in the scenario of the $1^{\text {st }}$ step. Then, generator 3 finds out that the external voltage contribution that it sees is no longer the same. Then, it performs the same action, resulting in the scenario of the $2^{\text {nd }}$ step. Then, generator 2 displaces again by the same reason, which results in the $3^{\text {rd }}$ step. If this sequence of actions continues, then after a certain amount of steps, local voltages (and output currents) will be very close to each other, so it can be assumed they are aligned, maximizing the current provided to the load. As a consequence, voltage $\mathbf{v}_{o}$ will be maximized and if generators provide currents with the same magnitude, then they will share the real and reactive powers demanded by the load.

The resulting voltage vector $\mathbf{v}_{O}$ is included in the diagram of each step on Fig. 5(b) in order to notice the angle differences with respect to the output current vectors of each VSC. Although it depends on the equivalent load, this provides an idea of how active and reactive powers of each VSC could behave at each step.

\section{INVERTER CONTROL STRATEGY}

A first approximation to the implementation of the proposed strategy is provided in this section and Fig. 6(a). In order to control the two-level three-phase inverter on the VSC topology as a current source, an hysteresis current control technique is employed [27], [28]. This controller is intended to maintain the three phase balanced currents within a maximum error band.

The current vector $\mathbf{i}_{o}^{s}$ is considered as the contribution of the local VSC to share the load of the power microgrid with the other operating VSCs. Thus, the available reference is not the inverter output current reference $\mathbf{i}_{i}^{s *}$ but the filter output current $\mathbf{i}_{O}^{s *}$.

$$
C_{f} \frac{d \mathbf{v}_{o}^{s}}{d t}=\mathbf{i}_{i}^{s}-\mathbf{i}_{o}^{s}
$$

The current that flows through the filter capacitor is given by (28). Quantities on a stationary $\alpha \beta$ reference frame can be transformed to a rotating $d q$ reference frame employing $\mathbf{v}^{s}=\mathbf{v}^{r} e^{j \omega t}$, where the superscript $r$ refers to rotative, and $\mathbf{v}^{r}$ is the representation of $\mathbf{v}^{s}$ on the rotative frame [9], [24]. $\omega t$ is the rotation angle measured from the stationary $\alpha$ axis. 


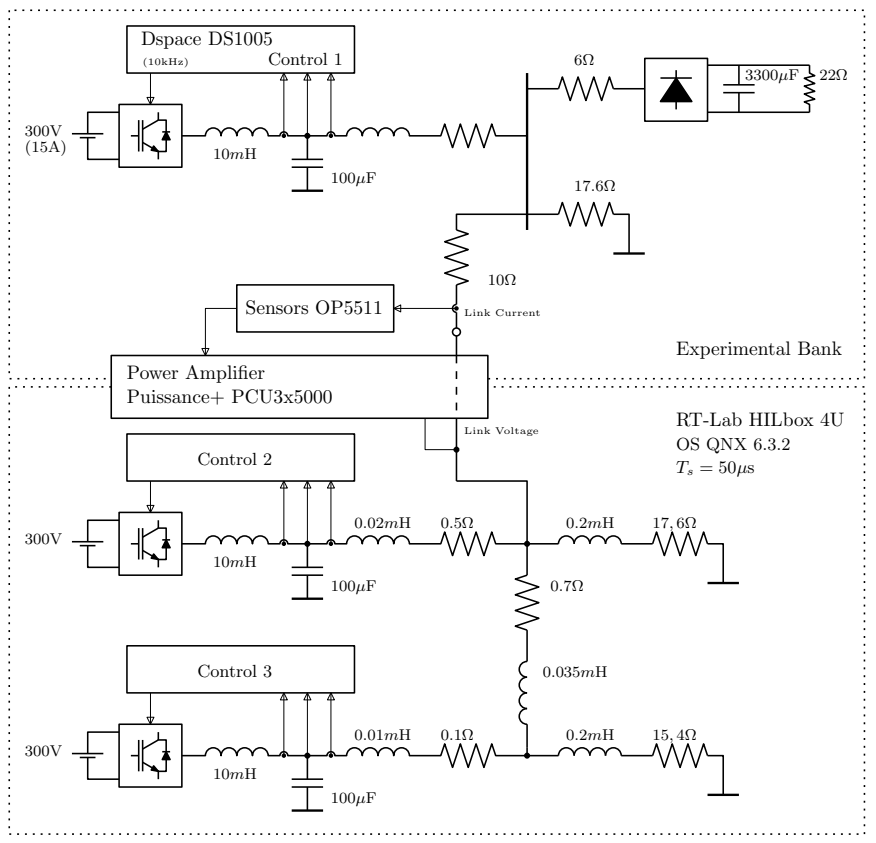

Fig. 7. Experimental Test grid for validation

Thus, the filter capacitor current on the rotative $d q$ frame is given by,

$$
C_{f} \frac{d \mathbf{v}_{o}^{r}}{d t}+j \omega C_{f} \mathbf{v}_{o}^{r}=\mathbf{i}_{i}^{r}-\mathbf{i}_{o}^{r}
$$

Thus, the inverter current $d q$ references can be computed from the output current $d q$ references by,

$$
\left\{\begin{array}{l}
i_{i d}^{*}=i_{o d}^{*}+C_{f} \frac{d v_{o d}}{d t}-\omega C_{f} v_{o q} \\
i_{i q}^{*}=i_{o q}^{*}+C_{f} \frac{d v_{o q}}{d t}+\omega C_{f} v_{o d}
\end{array}\right.
$$

These computations are performed on the block Inverter current reference of Fig. 6(a) which corresponds to Fig. 6(b). Inverter Current, Output Current and Output voltage $a b c$ quantities are measured, transformed to the $d q$ frame which rotates at a fixed frequency of $50 \mathrm{~Hz}$ and filtered to control only the fundamental positive sequence. A PI regulator is included to compensate steady state error on the $d q$ components of the output current and improve the data employed by the strategy.

On the other hand, the references are provided by the Output Power Control block on Fig. 6(a), whose methodology is explained here. This block performs the proposed strategy and provides the references for the output current fundamental positive sequence $\mathbf{i}_{o_{d} q}^{*}$, and the $d q$ components for compensation of harmonic currents $\mathbf{i}_{o_{d} q}^{h c}$. The block receives as inputs the computed instantaneous powers $p$ and $q$, the corresponding $d q$ filtered components of output current $\mathbf{i}_{o_{d q}}$ and voltage $\mathbf{v}_{o_{d q}}$ and the separated harmonic content of current and voltage in the $d q$ frame $\left(\mathbf{i}_{o_{d q}}^{h}\right.$ and $\left.\mathbf{i}_{o_{d q}}^{h}\right)$ [29]. The block modifies the angle of the output current reference with an small perturbation step $\Delta \phi_{i_{o}}$. The resulting active and reactive power deviations are applied to expressions (18) to (23) (also alternatively (25) and (26) can be applied). Thus, quantities $\mathbf{v}_{e x}, \phi_{e x}, \mathbf{Z}_{o}, \phi_{z_{o}}, \mathbf{v}_{l c}$ are obtained (the diagram of Fig. 3(a) can be constructed). Then, the output current references are modified again in order to
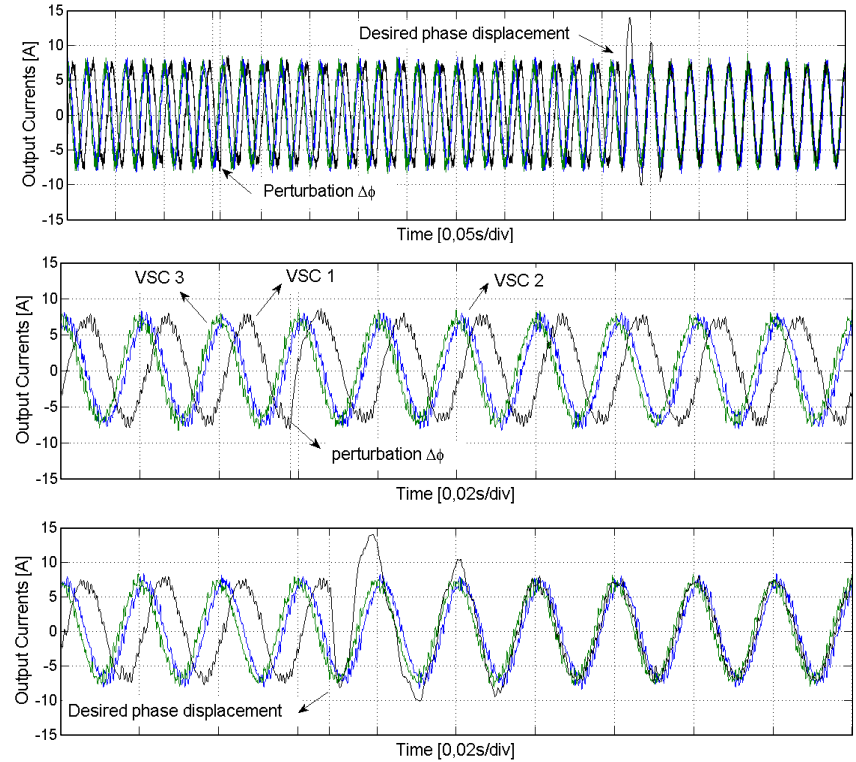

Fig. 8. Experimental perturbation-displacement scenario

achieve the power sharing objective (aligning the local voltage vector with the external voltage vector). On the other hand, the reference vector for compensation of harmonics is established with the obtained impedance $\mathbf{Z}_{o}$ as explained in section IV.

One VSC is chosen to be the reference VSC, the other VSCs will be the tracking VSCs and will perform the strategy.

With respect to Voltage regulation, once the tracking VSCs have found their equivalent impedances, their output current magnitudes can be fixed to a value inversely proportional to the magnitude of the impedance and the number of VSCs in the microgrid, and proportional to a desired magnitude of voltage $\left|\mathbf{v}_{o_{d q}}\right|^{*}$.

$$
\left|\mathbf{i}_{o_{d q}}\right|^{*}=\frac{\left|\mathbf{v}_{o_{d q}}\right|^{*}}{M\left|\mathbf{Z}_{o}\right|}
$$

The reference magnitude can be computed with (29) for the tracking VSCs, where $M$ is the total amount of VSCs. Since this reference is based on the assumption that the VSCs are sharing the demanded powers (Maximum Output Voltage Amplitude), the method will have an error until the tracker VSCs have found the reference VSC. The PI regulator on Fig. 6(c) is proposed for the reference VSC in order to reduce the error in steady state for the desired regulation magnitude of voltage.

\section{EXPERIMENTAL RESULTS}

In order to test the proposed strategy and its maximum output voltage amplitude alternative for power sharing, an experimental validation is proposed with the scheme shown on Fig. 7. This experimental microgrid consists of three VSCs, three linear loads and a three-phase diode bridge rectifier in a Real-Time(RT) Power Hardware-in-the-Loop (PHIL) test scheme. Two of the VSCs and two of the linear loads are RT emulated with an RT-LAB HILBox $4 U$ platform. This portion of the grid is modeled with MATLAB/Simulink and its parameters are included in the scheme. The third VSC, the 


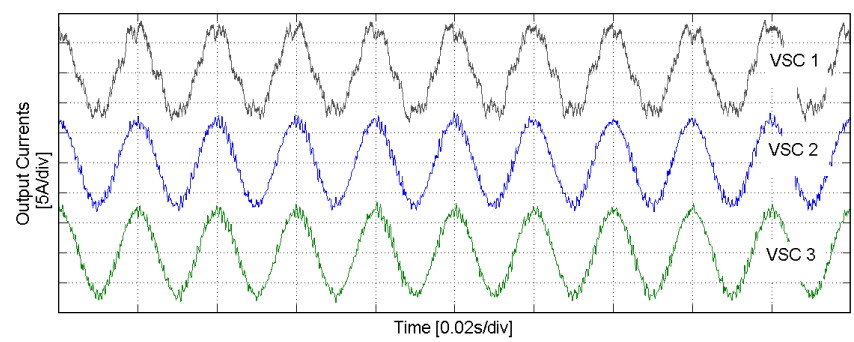

Fig. 9. Output currents (phase A) compensating harmonics of voltage during the experiment

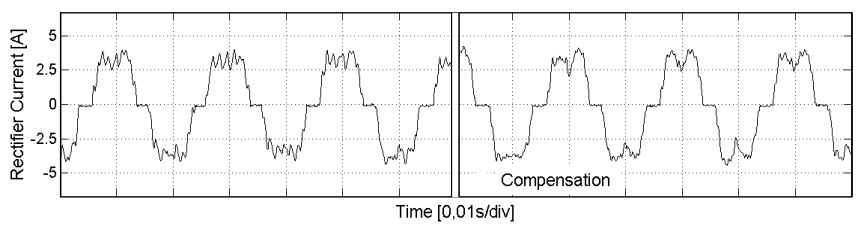

Fig. 10. Rectifier Current (phase A) before and after compensation

nonlinear load and the third linear-load are the PHIL devices. A three-phase power amplifier Puissance+ PCU $3 \times 5000$ is employed as power interface between the PHIL portion and the RT portion of the grid. The power amplifier provides a voltage while its output current is measured with OP5511 sensors to provide a power feedback loop to the RT portion of the grid (the power amplifier has an operating bandwidth from DC to $20 \mathrm{kHz}$ and a $5 \mathrm{kVA} /$ phase maximal power). There is no communication link between VSCs, the controller for the real inverter is implemented in MATLAB/Simulink and compiled for DS1005 dSpace target hardware. The RT VSCs controllers are implemented in MATLAB/Simulink as well, and the corresponding compilation is sent via TCP/IP to the $R T-L A B$ platform [30]-[32]. In this test, the output currents magnitudes are fixed to $7 \mathrm{~A}$ peak to easily show the performance of the proposed technique.

Fig. 8 shows a scenario (with linear load) where the RT VSC modifies its reference output current angle by a quantity $\Delta \phi_{i_{o}}=5^{\circ}$. This modification of the reference angle represents a perturbation to the grid. Then it computes a desired phase displacement based on the computed parameters $\left(\mathbf{v}_{e x}, \phi_{e x}\right.$, $\mathbf{Z}_{o}, \phi_{Z_{o}}, \mathbf{v}_{l c}$ ), and $400 \mathrm{~ms}$ later it rotates its current vector to the desired position. As it was mentioned on section $\mathrm{V}$, it the maximum output voltage amplitude alternative, each VSC tries to align its local voltage contribution vector with the external voltage contribution vector, resulting in a phase displacement relatively close to the other VSC's current vectors.

A similar test is performed with the nonlinear load. Once each tracking VSC has made its first perturbation, it can approximate its equivalent linear load. From this computation each VSC is able to compensate the harmonic content on the grid voltage. Also, with each perturbation it is able to update the value of $\mathbf{Z}_{o}$. Fig. 9 shows the phase $A$ output currents from each VSC performing the harmonic compensation. It is important to notice that the closeness of the VSC 1 filter capacitor to the nonlinear load forces it to attract more harmonic currents than the other capacitors, however the compensation

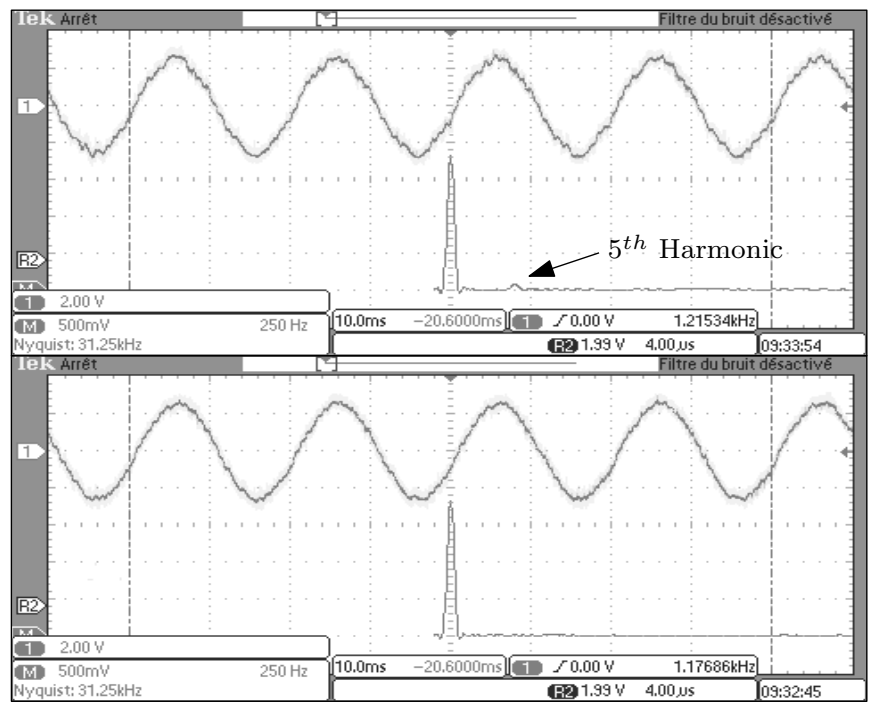

Fig. 11. Voltage of the power amplifier (phase A) before and after compensation

is performed by each tracking VSC as it can be seen on Fig. 9 . A contrast between compensation and non-compensation cases can be seen on Fig. 10 and Fig. 11 for the rectifier current and the amplifier output voltage. As it can be observed, the compensation eliminates a fifth-harmonic on the voltage and improves the rectifier current.

Under a certain amount of perturbations from the tracking VSCs, they are able to find the reference which is assigned to VSC 3. As it was mentioned before, when the trackers achieve to find the reference, then the active and reactive powers are shared. This can be observed in Fig. 12 where two cases are exposed for the filtered output power profiles. In both cases, the initial angle difference between VSC 2 and the reference VSC is $45^{\circ}$ (this value was arbitrary chosen for the experimental evaluation). In both cases, the initial angle difference between VSC 1 and the reference VSC is unknown because it depends on the non-synchronized initialization of both portions of the grid (physical and real-time emulated). In both cases it can be observed that the VSCs get close to the alignment of their currents, each providing a third part of the maximum power that can be delivered to the grid at a fixed $7 \mathrm{~A}$ peak current for each VSC. The impedance magnitude seen from the emulated VSCs is about $5,74 \Omega$, while the impedance seen from the real VSC is about $5,98 \Omega$. This implies an slight difference between the delivered active powers, which assuming an alignment of currents (21A peak), will be around $850 \mathrm{~W}$ per VSC.

A similar arbitrary case is registered for the reactive power. As it can be seen from Fig. 7, the demanded reactive power is very small, thus the proposed approach should make the VSCs to get close to zero reactive output power. The reactive power sharing is shown on Fig. 13. As it can be seen, after the fifth perturbation, the VSCs get very close to the desired output. It is also important to highlight that the time for perturbations is arbitrary chosen for the illustration of the approach. As it can be seen the time between perturbations can be smaller and each VSC can decide when to perturb depending on the error 

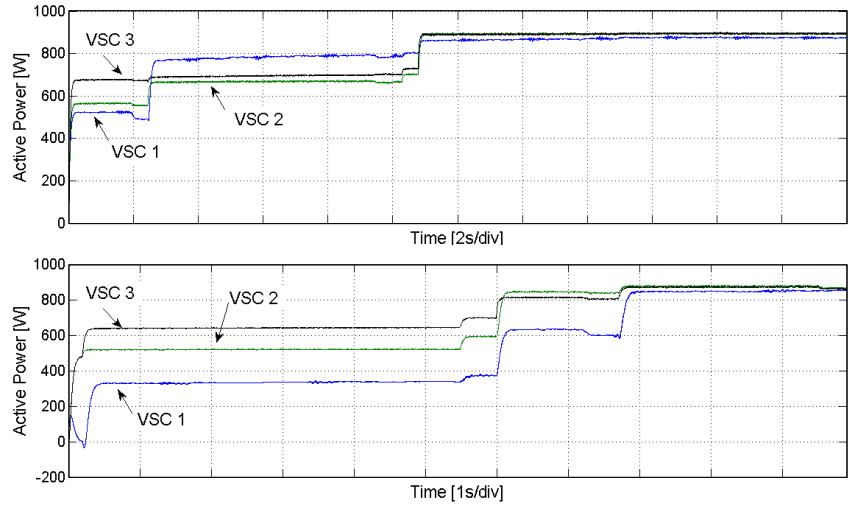

Fig. 12. Two experimental scenarios and the resulting active power sharing

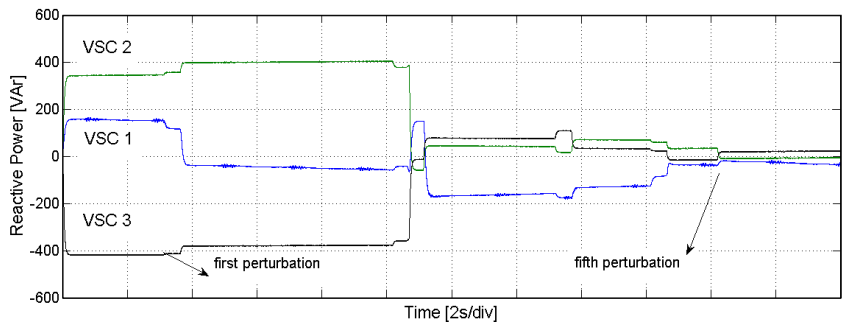

Fig. 13. The resulting reactive power sharing for an experimental scenario.

between its reference and its output.

\section{CONCLUSION}

A new strategy to control microgrids highly penetrated by Voltage Source Converters (VSC) and operating in stand-alone mode is proposed. The strategy is based on instantaneous measurements and calculations of voltages and currents and the application of Instantaneous Power Theory. This approach employs each VSC along with an LC filter as a current source. The grid parameters are not known by the controller, only the filter inductance and capacitance are known. The approach is capable of giving an approximation of the equivalent impedance of the system seen from the filter output, without difficult procedures or measurements. Additionally, it offers great versatility to control the generator and make profit from the different alternatives according to output powers. Results of the first approximation show the potential of the strategy. However, a more robust strategy to perturb the grid and automatically decide when to perturb should be further studied in order to improve the performance of the proposed strategy.Two alternative methods are provided to find an approximation to the angle of the external voltage contribution $\phi_{e x}$. Besides, every possible application derivable from this angle is detailed, under the proposed strategy. The methodology should be further studied in order to treat unbalanced conditions, however the experimental results have shown its potential application.

\section{REFERENCES}

[1] N. Hatziargyriou, H. Asano, R. Iravani, and C. Marnay, "Microgrids," Power and Energy Magazine, IEEE, vol. 5, no. 4, pp. 78-94, 2007.
[2] B. Kroposki, R. Lasseter, T. Ise, S. Morozumi, S. Papatlianassiou, and N. Hatziargyriou, "Making microgrids work," Power and Energy Magazine, IEEE, vol. 6, no. 3, pp. 40-53, 2008.

[3] N. Hatziargyriou, "Microgrids," Power and Energy Magazine, IEEE, vol. 6, no. 3, pp. 26-29, 2008.

[4] C. Sao and P. Lehn, "Autonomous load sharing of voltage source converters," IEEE Transactions on Power Delivery, vol. 20, no. 2, pp. 1009-1016, 2005.

[5] P. Divshali, S. Hosseinian, and M. Abedi, "Decentralised vsc-based microgrid's general power flow," International Review of Electrical Engineering, vol. 6, no. 7, pp. 3041-3050, 2011.

[6] N. Pogaku, M. Prodanovic, and T. Green, "Modeling, analysis and testing of autonomous operation of an inverter-based microgrid," IEEE Transactions on Power Electronics, vol. 22, no. 2, pp. 613-625, 2007.

[7] M. Bongiorno, J. Svensson, and A. Sannino, "Dynamic performance of vector current controllers for grid-connected vsc under voltage dips," in Conference Record of the 2005 Industry Applications Conference, Fourtieth IAS Annual Meeting, vol. 2, 2005, pp. 904-909 Vol. 2.

[8] L. Harnefors, M. Bongiorno, and S. Lundberg, "Input-admittance calculation and shaping for controlled voltage-source converters," IEEE Transactions on Industrial Electronics, vol. 54, no. 6, pp. 3323-3334, 2007.

[9] M. Monfared, S. Golestan, and J. Guerrero, "Analysis, design, and experimental verification of a synchronous reference frame voltage control for single-phase inverters," IEEE Transactions on Industrial Electronics, vol. 61, no. 1, pp. 258-269, 2014.

[10] A. Bergen and V. Vittal, Power Systems Analysis. Pearson/Prentice Hall, 2000.

[11] J. Glover, M. Sarma, and T. Overbye, Power Systems Analysis \& Design. Thomson, 2008.

[12] J. Guerrero, L. Garcia de Vicuna, J. Matas, M. Castilla, and J. Miret, "Output impedance design of parallel-connected ups inverters with wireless load-sharing control," IEEE Transactions on Industrial Electronics, vol. 52, no. 4, pp. 1126-1135, 2005

[13] J. Guerrero, M. Chandorkar, T. Lee, and P. Loh, "Advanced control architectures for intelligent microgrids;part i: Decentralized and hierarchical control," IEEE Transactions on Industrial Electronics, vol. 60, no. 4, pp. 1254-1262, 2013.

[14] R. Majumder, B. Chaudhuri, A. Ghosh, R. Majumder, G. Ledwich, and F. Zare, "Improvement of stability and load sharing in an autonomous microgrid using supplementary droop control loop," IEEE Transactions on Power Systems, vol. 25, no. 2, pp. 796-808, 2010.

[15] S. Chaudhary, R. Teodorescu, P. Rodriguez, P. Kjaer, and A. Gole, "Negative sequence current control in wind power plants with vsc-hvdc connection," IEEE Transactions on Sustainable Energy, vol. 3, no. 3, pp. 535-544, 2012.

[16] R. Ottersten and J. Svensson, "Vector current controlled voltage source converter-deadbeat control and saturation strategies," IEEE Transactions on Power Electronics, vol. 17, no. 2, pp. 279-285, 2002.

[17] J. Svensson, "Grid-connected voltage source converter - control principles and wind energy applications," Ph.D. dissertation, Department of Electric Power Engineering, Chalmers University of Technology, Sweden, 1998.

[18] J. He, Y. W. Li, J. Guerrero, F. Blaabjerg, and J. Vasquez, "An islanding microgrid power sharing approach using enhanced virtual impedance control scheme," IEEE Transactions on Power Electronics, vol. 28, no. 11, pp. 5272-5282, Nov 2013.

[19] J. He, Y. W. Li, and F. Blaabjerg, "Flexible microgrid power quality enhancement using adaptive hybrid voltage and current controller," IEEE Transactions on Industrial Electronics, vol. 61, no. 6, pp. 2784-2794, June 2014.

[20] J. Vasquez, J. Guerrero, M. Savaghebi, J. Eloy-Garcia, and R. Teodorescu, "Modeling, analysis, and design of stationary-reference-frame droop-controlled parallel three-phase voltage source inverters," IEEE Transactions on Industrial Electronics, vol. 60, no. 4, pp. 1271-1280, 2013.

[21] A. Etemadi, E. Davison, and R. Iravani, "A decentralized robust control strategy for multi-der microgrids 2014;part i: Fundamental concepts," IEEE Transactions on Power Delivery, vol. 27, no. 4, pp. 1843-1853, 2012.

[22] S.-J. Ahn, J. woo Park, I.-Y. Chung, S.-I. Moon, S.-H. Kang, and S.-R. Nam, "Power-sharing method of multiple distributed generators considering control modes and configurations of a microgrid," IEEE Transactions on Power Delivery, vol. 25, no. 3, pp. 2007-2016, 2010.

[23] J. Peas Lopes, C. Moreira, and A. Madureira, "Defining control strategies for microgrids islanded operation," IEEE Transactions on Power Systems, vol. 21, no. 2, pp. 916-924, 2006. 
[24] Y. Zhang and H. Ma, "Theoretical and experimental investigation of networked control for parallel operation of inverters," IEEE Transactions on Industrial Electronics, vol. 59, no. 4, pp. 1961-1970, 2012.

[25] M. Savaghebi, A. Jalilian, J. Vasquez, and J. Guerrero, "Autonomous voltage unbalance compensation in an islanded droop-controlled microgrid," IEEE Transactions on Industrial Electronics, vol. 60, no. 4, pp. 1390-1402, 2013.

[26] H. Akagi, E. Watanabe, and M. Aredes, Instantaneous Power Theory and Applications to Power Conditioning, ser. IEEE Press Series on Power Engineering. Wiley, 2007.

[27] M. Milosevic, "On the control of distributed generation in power systems," Ph.D. dissertation, Swiss Federal Institute of Technology, Zurich, Switzerland, Jun. 2007.

[28] M. Kazmierkowski and L. Malesani, "Current control techniques for three-phase voltage-source pwm converters: a survey," IEEE Transactions on Industrial Electronics, vol. 45, no. 5, pp. 691-703, 1998.

[29] A. de Heredia, P. Antoniewicz, I. Etxeberria-Otadui, M. Malinowski, and S. Bacha, "A comparative study between the dpc-svm and the multiresonant controller for power active filter applications," in 2006 IEEE International Symposium on Industrial Electronics, vol. 2, July 2006, pp. $1058-1063$.

[30] H. Gaztanaga, I. Etxeberria-Otadui, S. Bacha, and D. Roye, "Real-time analysis of the control structure and management functions of a hybrid microgrid system," in IECON 2006 - 32nd Annual Conference on IEEE Industrial Electronics, Nov 2006, pp. 5137-5142.

[31] D. Ocnasu, C. Gombert, S. Bacha, D. Roye, F. Blache, and M. S., "Real-time hybrid facility for the study of distributed power generation systems," in Revue des Energies Renouvables, 2008, pp. 343-356.

[32] C. Dufour, S. Cense, V. Jalili-Marandi, and J. Belanger, "Review of stateof-the-art solver solutions for hil simulation of power systems, power electronic and motor drives," in 2013 15th European Conference on Power Electronics and Applications (EPE), Sept 2013, pp. 1-12.

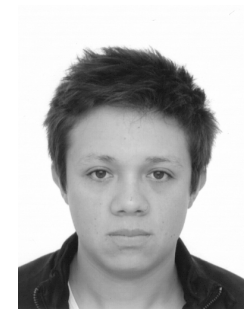

Andres Ovalle (S'12) was born in Tunja, Colombia, in 1990. He received a degree in Electronics Engineering (2011) and a degree in Electrical Engineering (2012) from the Universidad de los Andes, Bogotá, Colombia. In 2013, he received a M.Sc. degree in Electrical Engineering from the same institution. Currently, He works for the Grenoble Electrical Engineering Laboratory (G2ELab) and he is a Ph.D. student on the doctoral school EEATS (Electronique, Electrotechnique, Automatique et Traitement du Signal) from the University of Grenoble, Grenoble,

France. (email: andres.ovalle-villamil@g2elab.grenoble-inp.fr).

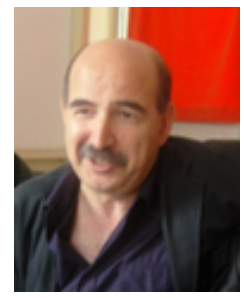

Seddik Bacha (M'08) received the B.E. and M.S. degrees from École National Polythecnique de $\mathrm{Al}-$ giers, Algiers, Algeria, in 1982 and 1990, respectively, and the Ph.D. degree from the Grenoble National Institute of Technology, Grenoble, France, in 1993. In 1990, he joined the Laboratoire d'Électrotechnique de Grenoble. In 1998, he was habilitated to conduct research. He is currently the manger of the Power Systems Group, Grenoble Electrical Engineering Laboratory (G2ELab), Grenoble National Institute of Technology, and is also a Professor with the Joseph Fourier University of Grenoble. His research interests include power electronics system modeling and control, power quality, and renewable energy integration. (email: seddik.bacha@g2elab.grenoble-inp.fr)

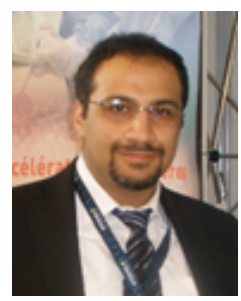

Ahmad Hably was born in Saida, Lebanon. He received the B.S. degree in electrical engineering from the Lebanese University and the Ph.D. degree in automatic control from the Grenoble Institute of Technology (Grenoble INP), Grenoble, France, in 2007. After one year as a Researcher at the Laboratoire dInformatique, de Robotique et de Microelectronique de Montpellier, he joined the Automatic Control Department, GIPSA-Lab, as an Associate Professor, Grenoble-INP. (email: ahmad.hably@gipsalab.grenoble-inp.fr)

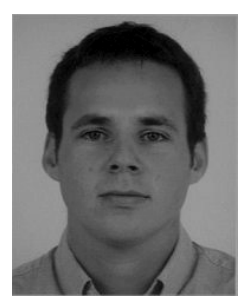

Axel Rumeau was born in Sao Caetano Do Sul, Brazil, in 1980. He received the M.Sc. degree in electronic devices and the Ph.D. degree in electrical engineering respectively in 2005 and 2009 from the University of Toulouse (France). Since 2010, he has been involved as an R\&D Engineer at Grenoble Electrical Engineering Laboratory (G2Elab) in rapid prototyping and real time simulation of electric power systems. (email: axel.rumeau@g2elab.grenoble-inp.fr)

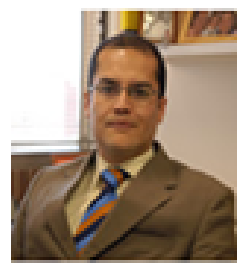

Gustavo Ramos (M04) received a degree in electrical engineer (1997) from Universidad Nacional, Manizales, Colombia and M.Sc. (1999) and PhD (2008) in Electrical Engineering from Universidad de Los Andes, Bogotá, Colombia. He is currently an Associate Professor with the Department of Electrical Engineering at School of Engineering, Universidad de Los Andes, Colombia, where is involved in teaching courses on power electronics, fundamentals of power systems, power quality, distribution and industrial systems design. He has authored 17 international journal papers and more than 50 conference proceedings papers. His current research interest include software-hardware platform to power systems simulation, advanced distribution automation, microgrids, transients in grounding systems: (email: gramos@uniandes.edu.co) 